\title{
The effect of controlling the ABC's of diabetes on cardiovascular disease in a community-based endocrinology practice
}

\author{
Swarna Varma ${ }^{1}$, Gretchen A. Piatt ${ }^{2^{\star}}$ \\ ${ }^{1}$ Pittsburgh Endocrinology and Diabetes Associates, Bridgeville, USA \\ ${ }^{2}$ University of Michigan Medical School, Ann Arbor, USA; *Corresponding Author: piattg@umich.edu
}

Received 30 September 2013; revised 24 October 2013; accepted 31 October 2013

Copyright (C) 2013 Swarna Varma, Gretchen A. Piatt. This is an open access article distributed under the Creative Commons Attribution License, which permits unrestricted use, distribution, and reproduction in any medium, provided the original work is properly cited.

\section{ABSTRACT}

Introduction: Large clinical trials demonstrate that glycemic, blood pressure, and cholesterol control lead to risk reduction in cardiovascular events. We determined whether A1c, blood pressure, and cholesterol control were associated with incident cardiovascular disease [CVD] in a community-based endocrinology practice over 10 years. Methods: 385 consecutive patients seen for diabetes management in a CBEP comprised the analysis cohort. To be included, a patient had $\geq 2$ A1c, blood pressure, and LDLc measurements respectively without prevalent CVD. All patients were 18 years or older with a diagnosis of diabetes before or during calendar year 2000. Results: $17.6 \%$ of patients developed incident CVD over 10 years. After controlling for age, gender, and time, patients who improved their $\mathrm{A} 1 \mathrm{c}$ to $<7 \%$ during the time they spent in the practice had a $47 \%$ reduction in incident CVD [hazard rate $=0.53,95 \% \mathrm{Cl}: 0.26-1.1$ ] Similar trends were observed for LDLc [27\% reduction, hazard rate $=0.73,95 \% \mathrm{Cl}: 0.3-1.8]$ and blood pressure control [35\% reduction, hazard rate $=0.65,95 \% \mathrm{Cl}: 0.33-1.3]$. Additionally, patients who achieved all ABCSs at goal level at least once were $2.5 x$ more likely not to develop incident CVD [hazard rate $=2.5,95 \% \mathrm{Cl}$ : $1.2,5.1]$ during their time in the practice. Conclusion: These results highlight the feasibility of achieving A1c, blood pressure, and cholesterol goals and demonstrate the significant impact that control has on incident CVD in a community-based endocrinology practice. Models of care that focus on prevention of complications through A1c, blood pressure, and cholesterol control may lead to decreased morbidity and mortality.

Keywords: Diabetes; Endocrinology; Community

\section{INTRODUCTION}

Mortality rates from cardiovascular disease are 2 - 4 times greater in people with diabetes than those without diabetes, with a similar risk for stroke [1]. Large clinical trials demonstrate that control of glycemic, blood pressure, and lipids [ABCs] leads to risk reduction in cardiovascular events. Indeed, glycemic control led to a $15 \%$ $33 \%$ risk reduction in the DCCT and UKPDS trials [2-4], while maintaining blood pressure with antiotensin converting enzyme inhibitors or blockers resulted in a $16 \%$ $50 \%$ risk reduction for cardiovascular events in the ASCOT, LIFE, HOPE and MICROHOPE trials [5-8]. Moreover, controlling lipids, specifically LDL cholesterol, led to a $19 \%-37 \%$ risk reduction in cardiovascular events and stroke as shown in several statin trials [9-13].

Despite the evidence for $\mathrm{ABC}$ control to reduce the risk of cardiovascular events in large clinical trials, translating these results into real-world clinical practice remains challenging, as demonstrated by national data. Over the past 10 years, only marginal gains in ABC conrol were observed. NHANES demonstrated improvements in glycemic control from $37 \%$ to $55.2 \%$, blood pressure from $35.2 \%$ to $51 \%$, and LDL from $32.9 \%$ to $52.9 \%$ over time [14]. Additionally, only $12.7 \%$ of people with diabetes in the US achieved all ABC goals simultaneously [15].

In the age of healthcare reform, where physicians are often evaluated by the proportion of their patients who achieve goal levels, it is critically important to under- 
stand whether the results demonstrated in large efficacy trials are able to be replicated in real world clinical practice with the same effect. Therefore, we aimed to determine whether glycemic [A1c $<7 \%$ ], blood pressure $[<130 / 80 \mathrm{mmHg}$ ], and cholesterol control [LDL $<100$ $\mathrm{mg} / \mathrm{dL}$ ] [ABCs] were associated with incident cardiovascular disease over 10 years in a community-based endocrinology practice. We hypothesize that risk factor control is associated with decreased cardiovascular disease risk over 10 years.

\section{METHODS}

The Chesapeake Institutional Review Board reviewed and approved this study. To investigate the effect of $\mathrm{ABC}$ control on incident cardiovascular disease [CVD], we employed a non-randomized, retrospective cohort design, where we identified four hundred consecutive patients seen in consultation for diabetes management in a community-based endocrinology practice, beginning in 2000 and followed through 2009. Five patients [1.25\%] were excluded for not meeting the most recent ADA diagnostic criteria of diabetes [16]. Data were collected for each individuals' office visits over 10 years [2000-2009] and transcribed into a database for analysis. In order to be included in the analysis cohort for this report, patients had to be18 years or older, had a diagnosis of diabetes [100\% diagnosed through ICD-9 codes, problem lists, or lab reports] before or during calendar year 2000, have at least two A1c, blood pressure, and LDL measurements, respectively, and be free of CVD.

CVD was defined as presence of myocardial infarction, stroke, transient ischemic attack, abnormal stress thallium, coronary artery bypass graft [CABG], congestive heart failure $[\mathrm{CHF}]$, cardiac catherization, or stent. 10 patients were excluded for having CVD at baseline. The final sample size for the cohort for these analyses was $n$ $=385$. Improvement in risk factor control was defined as moving from "not in goal range" to "in goal range" [A1c $<7 \%$, blood pressure $<130 / 80 \mathrm{mmHg}$, LDL $<100$ $\mathrm{mg} / \mathrm{dL}$ ] and maintaining that goal throughout the duration of time in the study. The final analysis cohort included 385 patients. No data were self reported.

\subsection{Patient Management}

As previously described [17], all patients received a detailed physical examination, including a foot exam, at each visit, as part of their ongoing clinical care. Principles of basal/bolus therapy were applied to patients on subcutaneous insulin, insulin pumps, or combination of insulin and oral agents, to target both fasting and postprandial hyperglycemia $[18,19]$. The same concept was simulated for patients on secretagogues, leading to use of meglitinides whenever accepted by the patient. Thia- zolidinedions and biguanides were used to decrease insulin resistance whenever not contraindicated $[4,20]$ [Table $1]$.

Table 1. Baseline demographic, clinical characteristics, and medication use of the study population [ $\mathrm{n}=385]$.

\begin{tabular}{|c|c|c|}
\hline & $\begin{array}{c}\text { Mean [SD] } \\
\text { or \% [n] }\end{array}$ & Range \\
\hline Age [years] & $60.4[14.8]$ & $20-89$ \\
\hline Duration [years] & $11.2[9.0]$ & $1-44$ \\
\hline Gender [\% male] & $59.2[231]$ & - \\
\hline Race [\% non-hispanic white] & $92.7[355]$ & - \\
\hline Type of diabetes [\% Type 1] & $15.9[61]$ & - \\
\hline Insulin $[\%$ yes $]$ & $63.8[252]$ & - \\
\hline BMI & $33.1[8.7]$ & $18-61$ \\
\hline $\mathrm{A} 1 \mathrm{c}[\%]$ & $7.4[1.5]$ & $4.7-13.8$ \\
\hline $\mathrm{A} 1 \mathrm{c}<7 \%[\%$ yes $]$ & $60.1[231]$ & - \\
\hline Systolic BP [mmHg] & $128.9[10]$ & $104-173$ \\
\hline Diastolic BP [mmHg] & $73.3[6.5]$ & $50-98$ \\
\hline Blood pressure $<130 / 80[\%$ yes $]$ & $44.9[173]$ & - \\
\hline $\mathrm{LDL}[\mathrm{mg} / \mathrm{dL}]$ & $93.6[29.4]$ & $27-273$ \\
\hline $\mathrm{LDL}<100 \mathrm{mg} / \mathrm{dL}$ & $73.3[281]$ & \\
\hline Antihypertensive medication [\% yes] & $92.9[367]$ & - \\
\hline ACE inhibitors & $46.3[183]$ & \\
\hline Angiotensin receptor blockers & $37.3[147]$ & \\
\hline Beta Blockers & $26.5[105]$ & \\
\hline Alpha-adrenergic blockers & $5.1[20]$ & \\
\hline Alpha agonists & $0.91[4]$ & \\
\hline Calcium channel blockers & 31.0 [122] & \\
\hline Diuretics & $28.1[111]$ & \\
\hline Vasodilators & $0.73[3]$ & \\
\hline Glucose lowering medication [\% yes] & $99.8[394]$ & - \\
\hline Insulin & $60.2[238]$ & \\
\hline Thiazolidinediones & $40.7[161]$ & \\
\hline Sulfonylureas & $20.8[82]$ & \\
\hline Meglitinitides & $54.3[214]$ & \\
\hline Biguanides & $17.3[68]$ & \\
\hline Alpha glucosidase inhibitors & $6.3[25]$ & \\
\hline Lipid lowering medications & & - \\
\hline Statins & $63.4[250]$ & \\
\hline Fibrates & $12.9[51]$ & \\
\hline Bile acid binding & $2.5[10]$ & \\
\hline Nicotinic acid & $0.7[3]$ & \\
\hline Cholesterol absorption inhibitor & $13.5[53]$ & \\
\hline
\end{tabular}


Physician charting used a four-page grid system, with medical problems and corresponding actions [prescribing or adjusting medications, instructions on diet, exercise, ordering appropriate labs and referrals to other specialists] in parallel columns. Type of diabetes, duration since diagnosis, A1C, blood pressure, lipid panels, and a complete review of systems were noted at each visit.

Office follow-up was scheduled in $1-2$ months for individuals not meeting all $\mathrm{ABC}$ goals and every $3-4$ months for individuals who were meeting all goals. Patients were encouraged to have laboratory work completed 8 - 10 days prior to their visit so that those results could be discussed during the office visit. During the office visit, simplified handouts that stated the diabetes national guidelines and their demonstrated risk reductions were given to the patients and discussed with them. A "team of four" philosophy, which included the patient, their family members, physician, and support staff was used to implement intensive therapy to achieve all $\mathrm{ABC}$ goals. The team was made aware that sub-optimal participation of any member could impede achievement of goals.

Additionally, patients received a single-page grocery shopping guide that included healthy food choices to encourage achieving satiety using an ad-lib, low-fat, lowglycemic, high fiber diet [21]. They were encouraged to read nutrition labels for calorie, fat, and sugar content and to increase physical activity.

Insulin-requiring patients [type 1 or type 2] were instructed to record blood glucose levels 2 - 4 times daily using a grid system to help visualize diurnal and nocturnal patterns. Directions were given on a single sheet with basal therapy and bolus doses using a baseline dose and instructions for correction doses according to a simple sliding scale, adding or subtracting $1-6$ units based on glucose readings. Instructions to use correction doses for prandial insulin to adjust for changes in physical activity, meal size and content were also given. Insulin pump therapy using similar principles was offered to patients with type 1 diabetes based on the physician's assessment of their capabilities [19]. Detailed instructions for preventing and treating hypoglycemia by adjusting the prandial insulin or secretagogue dose or by using simple sugars during an activity were given [22]. Glucose monitoring prior to driving or operating equipment was encouraged. Baseline doses were individualized and adjusted for each patient. All adjustments for prandial insulin, hypoglycemia treatment and prevention were based on an algorithm used in the practice, which was also modified when necessary. Patients using oral agents were instructed to record blood glucose levels at least 2 times daily using a similar grid system. Frequent phone contact with the CBEP [at least one phone call per week] was encouraged for all patients to allow the physician to make adjustments to the treatment regimen when needed in working to eachieve control of the ABCs of diabetes.

\subsection{Medication Usage}

Angiotensin-converting enzyme [ACE] inhibitors [8] and angiotensin receptor blockers [ARBs] [23] were preferentially used for blood pressure control or for treatment of nephropathy. Statins were used in patients with elevated LDL levels whenever possible for their cardiovascular protective effects $[9,24]$.

\subsection{Measures and Study Outcomes}

All subjects had height, weight, and blood pressure measured according to standard clinical practice methods. Alc and lipids were collected as part of the patients' routine clinical care through the patients' local hospital or through a commercial lab. CVD was tracked over the entire 10 years period. Medication lists were abstracted from all patient charts. Combination medications were separated into their individual components for purposes of classification.

\subsection{Statistical Analysis}

Measures of central tendency [e.g. proportions, means, standard deviations, medians, etc.] were used for all descriptive analyses. In determining if the proportion of subjects meeting $\mathrm{ABC}$ goals increased over time, a chisquare test for trend was used. Stepwise logistic regression was then used as a screening mechanism to identify if differences existed between the proportion of subjects who developed CVD and individual characteristics. Explanatory variables chosen for inclusion were not limited based on statistical significance but were based on literature review and analyses previously conducted in addition to the current analyses. Cox proportional hazards models with time-dependent covariates were used to analyze the effect of $\mathrm{ABC}$ control on incident CVD. All models controlled for age, gender, and A1c $<7 \%$, blood pressure $<130 / 80 \mathrm{mmHg}$, and $\mathrm{LDL}<100 \mathrm{mg} / \mathrm{dL}$, respectively. All analyses were conducted using SAS v.9.3, Cary, North Carolina.

Calculation of sample size was not completed prior to collection of data because the sample was collected for quality assurance/improvement purposes for the practice. However, with 385 subjects, we have $81 \%$ power to detect a $50 \%$ risk reduction in CVD in individuals who achieve A1c $<7 \%[\alpha=0.05]$.

\section{RESULTS}

\subsection{Population Characteristics}

Demographic and clinical characteristics of the cohort $[\mathrm{n}=385]$ are presented in Table 1 . The population in- 
cluded individuals with both type 1 [16\%] and type 2 [84\%] diabetes. The average age of the cohort was 60.4 \pm 14.8 years. The majority were male [59.2\%], non-Hispanic white [92.7\%], and currently using insulin [63.8\%] [Table 1]. Average diabetes duration was $11.2 \pm 9.0$ years and the average number of years an individual was a patient in the practice was $5.7 \pm 3.0$ years [Table 1]. The study cohort was representative of the community, in which the practice is located, which has approximately $23 \%$ of residents over 65 years of age and is predominantly caucasian $[92.2 \%]$.

At baseline, $60.1 \%, 44.9 \%$, and $73.3 \%$ of the cohort met the goal for A1c, blood pressure, and LDLc. Nearly all individuals were treated with at least one antihypertensive medication [92.9\%], and/or glucose lowering medication [99.8\%], and/or lipid lowering medication [87.1\%] [Table 1]. A previous report compared A1c, blood pressure, and cholesterol control to the national data [17] and demonstrated that significantly more patients met the goal of $\mathrm{A} 1 \mathrm{C}<7 \%$ in the CBEP compared to national estimates [CBEP: $47.1 \%$ vs. NHANES 19992000: $37 \%, p=0.003$ ]. Similar patterns were observed for blood pressure, total cholesterol, and control of all three ABCs.

\subsection{Incident Cardiovascular Disease and ABC Control}

From 2000-2009, 17.6\% [n $=68]$ of patients developed incident CVD. In those who developed CVD, the average time to event was $4.9 \pm 3.3$ years. There were no statistically significant differences in baseline A1c $<7 \%$ between individuals who developed CVD and those who did not develop CVD [Figure 1]. Only slight differences were apparent for $\mathrm{LDL}<100 \mathrm{mg} / \mathrm{dL}$, with a greater proportion of individuals with CVD meeting LDL goals

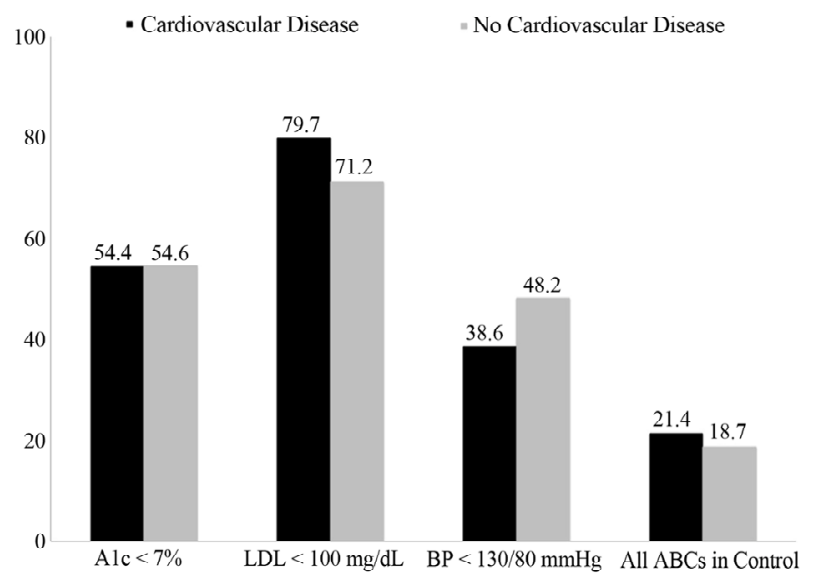

Figure 1. Baseline risk factor control in individuals who developed incident cardiovascular disease compared to individuals who did not develop incident cardiovascular disease, $\mathrm{n}=$ 385 . levels at baseline. Additionally, a greater proportion of individuals with CVD also had all ABCs in control at baseline in comparison to those without CVD [Figure 1].

When the effect of improvement [moving from "not controlled to goal levels" to "controlled to goal levels"] in $\mathrm{ABC}$ control on incident CVD was examined, trends in risk reducton were observed for $\mathrm{A} 1 \mathrm{c}<7 \%$, blood pressure $<130 / 80 \mathrm{mmHg}, \mathrm{LDL}<100 \mathrm{mg} / \mathrm{dL}$, and all ABCs in control [Table 2]. Patients who improved their A1c to the goal level at least once while they were a patient in the practice, experienced a $47 \%$ risk reduction in developing CVD [HR $=0.53$, 95\% CI: $0.26-1.1]$. Similarly, patients who improved their LDL and blood pressure to goal levels experienced a $27 \%[\mathrm{HR}=0.73,95 \% \mathrm{CI}: 0.3-$ $1.8]$ and $35 \%[\mathrm{HR}=0.65,95 \% \mathrm{CI}: 0.33-1.3]$ risk reduction in incident CVD, respectively. Most notably, however, were the patients who improved all three ABCs to goal levels at least once. These individuals were two and half times more likely to experience a statistically significant risk reduction in CVD over time $[\mathrm{HR}=2.5$, 95\% CI: 1.2 - 5.1] [Table 2].

\section{DISCUSSION}

In this 10 year retrospective analysis, which aimed to determine whether glycemic [A1c $<7 \%$ ], blood pressure [ $<130 / 80 \mathrm{mmHg}$, and lipid control [LDL $<100 \mathrm{mg} / \mathrm{dL}]$ [ABCs] was associated with incident coronary heart disease over 10 years in a community-based endocrinology practice, we demonstrated the feasibility of achieving $\mathrm{ABC}$ goals above the national average and the significant impact that $\mathrm{ABC}$ control has on incident $\mathrm{CVD}$ in clinical practice. Additionally, the results demonstrate that the greatest impact in reducing CVD is observed when all three risk factors are controlled.

The results of this report are comparable to the work of others in that goal attainment was similar to the national average for A1c, but subtantially higher for blood pressure, LDL and all ABCs [14]. Although the effect of A1C, LDL and BP control individually, did not show statistically significant risk reduction for CVD, patients with all ABCs in control were $250 \%$ less likely to develop incident CVD over time. This is consistent with

Table 2. Risk factor control and 10 year risk of incident cardiovascular disease, $\mathrm{n}=385$.

\begin{tabular}{ccccc}
\hline & Beta & p-value & $\begin{array}{c}\text { Hazard } \\
\text { rate }\end{array}$ & 95\% CI \\
\hline A1c $<7 \%$ & -0.63 & 0.09 & 0.53 & $0.26-1.1$ \\
LDLc $<100 \mathrm{mg} / \mathrm{dL}$ & -0.32 & 0.49 & 0.73 & $0.30-1.8$ \\
Blood pressure $<130 / 80 \mathrm{mmHg}$ & -0.43 & 0.23 & 0.65 & $0.33-1.3$ \\
All ABCs at goal level & 0.92 & 0.01 & 2.5 & $1.2-5.1$ \\
\hline
\end{tabular}

p-values obtained with cox proposal hazards models. 
the $59 \%$ relative risk reduction seen in the 13.3 years of follow up in the Steno 2 study, with multifactorial intervention [25]. The lowest incidence of any diabetes related endpoint, was reported in UKPDS 75, when optimal glycemic and blood pressure control was achieved, again demonstrating the importance of achieving control of multiple risk factors [26]. Intensive glycemic control alone, for 3.5 - 5.6 years, in the ACCORD, VADT and ADVANCE studies, did not result in risk reduction for cardiovascular events. [27], again, demonstating the importance for all $\mathrm{ABCs}$ to be in control.

In conducting real world research, there are a number of limitations that may effect the results. The data for this report was retrospective and limited to only one community-based endocrinology practice; therefore limiting the generalizability of the results. Additionally, one may argue that as a large proportion of patients had Alc $<7 \%$, rates of hypoglycemia may be high. Every attempt was made to prevent and treat hypoglycemia. Although 47\% of our cohort maintained $\mathrm{A} 1 \mathrm{C}$ at goal over the 10 years, there was no correlation between frequency of glucose readings $<80 \mathrm{mg} / \mathrm{dl}$ and glycemic control [data not shown]. This is in contrast to the $2-3$ times greater incidence of hypoglycemia reported in the intensive arm of ACCORD, ADVANCE, VADT, UKPDS and DCCT trials $[2,4,27]$. The same pattern is evident with weight gain and glycemic control. Unlike the significant weight gain observed in the intensively treated groups in the DCCT, UKPDS, ACCORD and VADT trials [2,4,27] weight levels of our patients remained steady over the 10 year study period. Other limitations include the relatively small amount of demographic, behavioral, and psychosocial data collected as part of chart review.

\section{CONCLUSION}

Healthcare providers and policy makers increasingly recognize the need for studies that examine long term diabetes management in real world settings, so that effective clinical and policy-level decisions can be made regarding diabetes care. These data provide one of the few reports of the effect of long-term diabetes management on incident CVD in clinical practice. Implementation of models of care that focus on secondary prevention of complications may lead to decreased morbidity and mortality and may have a significant impact in reversing the projected increases in diabetes related complications, mortality, and annual expenditures.

\section{ACKNOWLEDGEMENTS}

No funding was used for the completion of this work.

The authors would like to disclose that Dr. Varma is on the speaker's bureau for NovoNordisk, Eli Lilly, Aventis, Pfizer, AstraZeneca, Abbott, Kos, Novartis, King, Merck, Glaxo SmithKline, Takeda Pharmaceuti- cals, and has received consultancy fees from NovoNordisk, Amylin, and Glaxo SmithKline Pharmaceuticals. Dr. Varma also holds stock options in Amylin Pharmaceuticals. Dr. Piatt does not have any conflicts of interest.

\section{REFERENCES}

[1] (2013) Heart Disease and Stroke Statistics - 2013 Update. Circulation, e82-e92.

[2] The Diabetes Control and Complications Trial/Epidemiology of Diabetes Interventions and Complications [DCCT/ EDIC] Study Research Group (2005) Intensive diabetes treatment and cardiovascular disease in patients with type 1 diabetes. New England Journal of Medicine, 353, 26432637.

[3] Holman, R.R., Paul, S.K. and Bethel, M.A. (2008) 10 year follow up of intensive glucose control in type 2 diabetes. New England Journal of Medicine, 359, 1577-1589. http://dx.doi.org/10.1056/NEJMoa0806470

[4] UKPDS 34. (1998) Effect of intensive blood glucose control with metformin on complications in overweight patients with type 2 diabetes. Lancet, 352, 854-865. http://dx.doi.org/10.1016/S0140-6736(98)07037-8

[5] Sever, P.S., et al. (2012) Is plama renin activity a biomarker for the prediction of renal and cardiovascular outcomes in treated hypertensive patients: Observations from the Anglo-Scandinavian Cardiac Outcomes Trial [ASCOT]. European Heart Journal, 33, 2970-2979. http://dx.doi.org/10.1093/eurheartj/ehs241

[6] Dahlof, B., Devereux, R.B., Kjeldsen, S.E., Julius, S., Beevers, G. and de Faire, U. (2002) Cardiovascular morbidity and mortality in the Losartan Intervention For Endpoint reduction in hypertension study [LIFE]: A randomised trial against atenolol. Lancet, 359, 995-1003. http://dx.doi.org/10.1016/S0140-6736(02)08089-3

[7] Heart Outcomes Prevention Evaluation [HOPE] Study Investigators (2000) Effects of ramipril on cardiovascular and microvascular outcomes in people with diabetes mellitus: Results of the Hope study and MICRO-HOPE substudy. Lancet, 355, 253-259.

[8] Arnold, J.M.O., Yusuf, S., Young, J., et al. (2003) Prevention of heart failure in patients in the heart outcomes provention evaluation (HOPE) study. Circulation, 107, 1284-1290.

[9] Heart Protection Study Collaborative Group (2003) MRC/BHF Heart Protection Study of Cholesterol lowering with Simvastatin in 5963 people with diabetes. Lancet, 361, 2005-2016. http://dx.doi.org/10.1016/S0140-6736(03)13636-7

[10] Pyorola, K., Pedersen, T.R., Kjekshus, J., Faergeman, O., Olsson, A.G. and Thorgiersson, G. (1997) Cholesterol lowering with simvastatin improves prognosis of diabetic patients with coronary heart disease. Diabetes Care, 20, 614-620. http://dx.doi.org/10.2337/diacare.20.4.614

[11] The Long-Term Intervention with Pravastatin in Ischaemic Disease [LIPID] (1998) Study group of cardiovascular events and death with pravastatin in patients with coronary heart disease and a broad range of initial cho- 
lesterol levels. New England Journal of Medicine, 339, 1349-1357.

[12] Treating to New Targets [TNT] Investigators (2005) Intensive lipid lowering with atorvastatin in patients with stable coronary disease. New England Journal of Medicine, 352, 1425-1435.

[13] Sacks, F.M., Tonkin, A.M., Craven, T., Pfeffer, M.A., Shepherd, J. and Keech, A. (2002) Coronary heart disease in patients with low ldl cholesterol. Circulation, 105, 1446-1452.

http://dx.doi.org/10.1161/01.CIR.0000012918.84068.43

[14] Ford, E.S. (2011) Trends in the control of risk factors for cardiovascular disease among adults with diagnosed diabetes: Findings from the NHANES survey 1999-2008. Journal of Diabetes, 3, 337-347. http://dx.doi.org/10.1111/j.1753-0407.2011.00148.x

[15] Wong, K., et al. (2012) Comparison of demographic factors and cardiovascular risk factor control among us adults with type 2 diabetes by insulin treatment classification. Journal of Diabetes Complications, 26, 169-174. http://dx.doi.org/10.1016/i.jdiacomp.2012.03.006

[16] American Diabetes Association (2013) Standards of medical care in diabetes. Diabetes Care, 36, S11-S66. http://dx.doi.org/10.2337/dc13-S011

[17] Varma, S., Boyle, L., Varma, M. and Piatt, G. (2008) Controlling the ABCs of diabetes in clinical practice: A community-based endocrinology practice experience. Diabetes Research and Clinical Practice, 80, 89-95. http://dx.doi.org/10.1016/j.diabres.2007.10.029

[18] DECODE Study Group on Behalf of the European Diabetes Epidemiology Group (2001) Glucose tolerance and cardiovascular mortality. Comparison of fasting and 2hour diagnostic criteria. Archives of Internal Medicine, 161, 397-405. http://dx.doi.org/10.1001/archinte.161.3.397

[19] Nathan, D.M. (2002) Initial management of glycemia in type 2 diabetes mellitus. New England Journal of Medicine, 347, 1342-1349. http://dx.doi.org/10.1056/NEJMcp021106

[20] Olefsky, J.M. (2000) Treatment of insulin resistance with peroxisome proliferators activated receptor gamma agonist. Journal of Clinical Investigation, 106, 6467-6472. http://dx.doi.org/10.1172/JCI10843

[21] Knoops, K.T., de Groot, L., Kromhout, D., Perrin, A., Varela, O. and Menotti, A. (2004) Mediterranean diet, lifestyle factors, and 10 year mortality in elderly European men and women. JAMA, 292, 1433-1439. http://dx.doi.org/10.1001/jama.292.12.1433

[22] Bolli, G.B. (2006) Physiological insulin replacement needed to limit hypoglycemia. Diabetes Care, 29, 1707 1709. http://dx.doi.org/10.2337/dc06-0716

[23] Brenner, B.M., Cooper, M.E., de Zeeuw, D., Keane, W.F., Mitch, W.E. and Parving, H.H. (2007) Effects of losaartan on renal and cardiovascular outcomes in patients with type 2 diabetes and nephropathy. New England Journal of Medicine, 345, 861-869.

[24] Colhoun, H.M., Betteridge, D.J., Durrington, P.N., Hitman, G.A., Neil, H. and Livingstone, S.J. (2004) Primary prevention of cardiovascular disease with atorvastatin in type 2 diabetes in the collaborative atorvastatin diabetes study [CARDS]. Lancet, 364, 685-696. http://dx.doi.org/10.1016/S0140-6736(04)16895-5

[25] Gaede, P., Lund-Anderson, H., Parving, H.H. and Pedersen, O. (2008) Effect of a multifactorial intervention on mortality in type 2 diabetes. New England Journal of Medicine, 358, 580-591. http://dx.doi.org/10.1056/NEJMoa0706245

[26] Stratton, I.M., Cull, C.A., Adler, A.I., Mathews, D.R., Neil, H.A.W. and Holman, R.R. (2006) Additive effects of glycemia and blood pressure exposure on risk of complications in type 2 diabetes UKPDS 75. Diabetologia, 49, 1761-1769. http://dx.doi.org/10.1007/s00125-006-0297-1

[27] Skyler, J.S., Berganstal, R.B., Bonow, R.O., Buse, J., Deedwania, P., Gale, E.A.M., Howard, B.V., Kirkman, M.S., Kosiborod, M., Reaven, P. and Sherwin, R.S. (2009) Intensive glycemic control and the prevention of cardiovascular events: Implications of the ACCORD, ADVANCE, and VA Diabetes Trials. Diabetes Care, 32, $187-$ 192. http://dx.doi.org/10.2337/dc08-9026 